\title{
COMENTARIOS AL NUEVO RÉGIMEN DE AGUAS SUBTERRÁNEAS A PARTIR DE LA REFORMA AL CÓDIGO DE AGUAS DE 2005
}

\author{
Edesio CARrasco QUiroga*
}

RESUMEN: Este trabajo trata acerca del nuevo régimen de aguas subterráneas que comenzó a regir a partir de la reforma al Código de Aguas de fecha 16 junio de 2005. Junto con comentar y analizar cada una de las nuevas disposiciones que la modificación legal introdujo al título referido a las aguas subterráneas, se analiza la Resolución $N^{\circ} 341$ de la Dirección General de Aguas que complementó dicha reforma, haciéndose especial mención a los mayores márgenes de discrecionalidad administrativa introducidos por medio de ambas regulaciones. Para terminar, se concluye lo insuficiente que fue dicha reforma, al menos en lo que a aguas subterráneas se refiere, debido a que buena parte de su actual regulación descansa en una norma de carácter administrativo y no en una norma de rango legal, tal como debe ser.

Palabras Clave: Aguas subterráneas - Dirección General de Aguas (DGA) - Discrecionalidad administrativa.

\section{COMMENTARIES TO THE NEW GROUND WATERS REGIME AS OF THE 2005 WATER CODE REFORM}

ABSTRACT: This work deals with the new ground waters regime which started to rule from the beginning of the Water Code reform dated June 16, 2005. Together with analyzing and making remarks on each of the different new dispositions the legal modification introduced to the mentioned title concerning ground waters, Resolution $N^{\circ} 341$ of the General Administration of Waters has been analyzed. It complements said reform, especially mentioning the bigher margins of discretionary administration introduced through both regulations. In summary the mentioned reform was insufficient, at least concerning ground waters due to the fact that an important part of its current

Abogado, Licenciado en Derecho por la P. Universidad Católica de Chile. Profesor Ayudante de Derecho, Economía y Mercado en la Facultad de Derecho de la P. Universidad Católica de Chile. Correo electrónico: ecarrasco@abcia.cl

Agradezco los comentarios de Matías Desmadryl Lira.

Fecha de recepción: 2 de mayo de 2007.

Fecha de aprobación: 24 de septiembre de 2007. 
regulation rests on an administrative norm and not on a legal norm, as it should be.

KEY WORDS: Ground waters - General Administration of Waters (DGA) - discretionary administration.

SUMARIO: Introducción. I. Exploración de aguas subterráneas y remate ante solicitudes contemporáneas (artículo 58). II. Preferencia en el otorgamiento del derecho de aguas subterráneas (artículo 58 bis nuevo). III. Aspectos administrativos que complementan las reformas a los artículos 58 incisos segundo y tercero y 58 bis. IV. Declaración de probibición y comunidad de aguas (Articulo 63). V. Aspectos administrativos que complementan la reforma al artículo 63 del Código de Aguas. VI. Declaración de oficio de la DGA en la determinación de una zona de restricción (artículo 65). VII. Recarga artificial de acuíferos (artículo 66). VIII. Recarga artificial y consolidación de derechos de aprovechamiento de aguas provisionales (articulo 67). IX. Aspectos administrativos que complementan la reforma a los artículos 65, 66 y 67 del Código de Aguas. Explotación de aguas subterráneas. A. Declaración de una zona de restricción. B. Otorgamiento de derechos provisorios. C. Recarga artificial de acuíferos. Conclusión. Bibliografía citada.

\section{INTRODUCCIÓN}

Luego de trece años de discusión legislativa, el 16 de junio de 2005 , fueron aprobadas importantes reformas al Código de Aguas. Con ello, se puso término a 13 años de discusión y tramitación del proyecto, el que, una vez aprobado, estableció una nueva institucionalidad en materia de, derechos de agua. De esta forma, el pago de una patente por el no uso de las aguas; la modificación al sistema de concesión de derechos al exigirse una memoria explicativa en la que se justifique el agua que se necesita extraer, según su uso; el otorgamiento de facultades a la Dirección General de Aguas (en adelante "DGA") en materia ambiental al poder declarar caudales ecológicos mínimos; al establecer nuevas obligaciones a los Conservadores de Bienes Raíces en relación con el Catastro Público de Aguas; y al perfeccionar el procedimiento de regularización de títulos, entre otros cambios, configura un nuevo escenario en el que el mercado de los derechos de agua se verá envuelto. Es en este contexto en que se insertan, también, sustanciales cambios en materia de aguas subterráneas, los cuales alteran en parte el sistema previo a la reforma.

Por medio de este artículo se comenta y analiza el nuevo régimen de aguas subterráneas surgido a partir de la modificación ya señalada, concentrándose específicamente a la alteración sufrida por el título VI "De las Aguas Subterráneas" del Código de Aguas y los aspectos administra- 
tivos que complementan dicha reforma por medio de la Resolución $\mathrm{N}^{\circ}$ 341 de 2005 de la DGA.

\section{EXPLORACIÓN DE AGUAS SUBTERRÁNEAS Y REMATE ANTE SOLICI- TUDES CONTEMPORÁNEAS (ARTÍCULO 58)}

El artículo 58 del Código de Aguas sufrió una importante reforma, pues contempla, a partir de ahora, el mecanismo de remate como solución a peticiones de exploración de aguas subterráneas contemporáneas. Esta nueva disposición señala lo siguiente:

Inciso Segundo. "Si dentro del plazo establecido en el inciso primero del artículo 142 se bubieren presentado dos o más solicitudes de exploración de aguas subterráneas sobre una misma extensión territorial de bienes nacionales, la $\mathrm{Di}$ rección General de Aguas resolverá la adjudicación del área de exploración mediante remate entre los solicitantes. Las bases de remate determinarán la forma en que se llevará a cabo dicho acto, siendo aplicable a su respecto lo dispuesto en los artículos 142, 143 y 144, en lo que corresponda".

Es adecuado que se haya utilizado el remate, eficiente técnica de mercado, como mecanismo de solución ante solicitudes contemporáneas de exploración de aguas subterráneas. Interesante es destacar que este instrumento restringe de manera importante la discrecionalidad administrativa $^{1}$ de la DGA, otorgando mediante un mecanismo subsidiario la posibilidad a los particulares de adjudicarse los derechos de agua que estén sometidos a dicho procedimiento. En consecuencia, serán ellos mediante sus posturas quienes determinarán quién y a qué precio se adjudica el derecho a explorar aguas subterráneas en una extensión territorial de propiedad fiscal.

A futuro, sería conveniente que pudiese someterse a remate no solo el derecho sobre las aguas alumbradas, sino que junto a ello, el área de

\footnotetext{
Para efectos de este trabajo, se entiende por discrecionalidad administrativa como aqueIla habilitación del legislador "a la administración en el ejercicio de las potestades jurídicas tendientes a satísfacer las necesidades públicas", habiendo ausencia de esta, cuando el quién (titular del órgano); el cómo (procedimiento); el porqué (motivo de actuar); el cuándo (momento u oportunidad); y el para qué (finalidad) están expresamente descritas en la ley. Respecto al qué (decisión adoptada por la autoridad), el legislador, para evitar la discrecionalidad de la que se hace referencia, debe establecer un mecanismo de actuar concreto (potestad reglada); o "bien puede conferir a la Administración un margen de libre apreciación para elegir la decisión más adecuada, razonable, proporcionada e idónea, que permita satisfacer de la mejor forma posible la necesidad pública de que se trata...", en la medida que cumpla con la finalidad de bien común que la Constitución y la ley prescriben. Soto Kloss, Eduardo (1982) El Recurso de Protección. Orígenes, doctrina y jurisprudencia, Santiago: Editorial Jurídica de Chile, p. 189; y Alarcón Jaña, Pablo (2000) Discrecionalidad Administrativa. Un estudio de la jurisprudencia chilena. Santiago: LexisNexis, pp. 87-88.
} 
exploración sobre la cual ellas son extraídas, haciendo realidad el principio de la "reserva estatal de bienes", el que es una excepción en nuestro derecho (artículo $19 \mathrm{~N}^{\circ} 23$ de la Constitución), transformándose así, en efectiva, la "libre apropiabilidad" de los bienes².

De esta manera, si dentro del plazo que establece el artículo 142 (seis meses, contados desde la presentación de la solicitud) se hubiesen presentado dos o más solicitudes de exploración sobre la misma extensión territorial, y no hubiese recursos hídricos suficientes para satisfacer dichos requerimientos, la DGA, una vez reunidos los antecedentes que acrediten la existencia de aguas disponibles para la constitución de nuevos derechos sobre ellas, citará a un remate. Se termina así, con la situación previa a la reforma, esto es, que cuando se solicitaban dos o más peticiones de exploración de aguas subterráneas en un área determinada, y estás se superponían, se le otorgaba el derecho al primero que las pedía, lo que alentaba la especulación. Con la modificación propuesta, la superposición se resuelve mediante remate.

En consecuencia, la reforma permite que más interesados puedan participar en el proceso de remate, situación que para las solicitudes de exploración de aguas subterráneas, antes no era posible. A partir de ahora el incentivo también estará puesto en dicho tipo de petición.

No obstante, este remate es solo posible cuando dos o más solicitudes de exploración de aguas subterráneas recaen sobre una misma extensión territorial de bienes nacionales de uso público. Por lo tanto, no es procedente cuando estas postulaciones recaen sobre un inmueble particular, pues en ese caso solo el dueño o un tercero, con autorización de este, tiene derecho a realizar exploraciones en dichas aguas (artículo 58 inciso cuarto).

Pese a lo conveniente de la institución del remate como mecanismo de solución, se comete una imprecisión al referirse a los "bienes nacionales de uso público", pues tal como lo reconoce Vergara ${ }^{3}$, la formulación del término en dicho artículo es "ambigua", debiendo haberse utilizado en vez de la expresión "bienes nacionales", la expresión "bienes fiscales", pues es el Fisco, y no la nación toda, el dueño de dichos terrenos. Es decir, solo en los terrenos sobre los cuales el Fisco sea dueño, y siempre que se

2 En relación a este principio, es clarísimo que "esta garantía ha sido establecida con el objeto de asegurar el libre acceso, a fin de hacer ingresar al dominio privado de las personas, a cualquier título lícito, toda clase de bienes, sean muebles o inmuebles, corporales o incorporales, y, en general, de todas las cosas susceptibles de ser incorporadas a un patrimonio personal, y proteger así a las personas de actos legislativos o de autoridad que las excluyan de este libre acceso a alguna categoría de bienes". VERDUGO MARINKOVIC, Mario y otros (1994) Derecho Constitucional. Tomo I. Santiago: Editorial Jurídica de Chile, p. 296.

3 Vergara Blanco, Alejandro (2004) "Discrecionalidad administrativa y nuevas limitaciones a los derechos de aguas". Puntos de Referencia. CEP, N²76, p. 3. 
presenten dos o más solicitudes de exploración sobre dichos terrenos, procederá el remate.

Esta reforma también le da coherencia a la disciplina del derecho de aguas, pues contempla un mecanismo de solución único, aplicable tanto para aguas superficiales como subterráneas ante peticiones contemporáneas de exploración, lo que refuerza el principio de la igualdad "en" la ley consagrado en el artículo $19 \mathrm{~N}^{\circ} 2$ de la Constitución ${ }^{4}$, pues la ley, en este caso el Código de Aguas, trata de manera justa y con un criterio de razonabilidad y similitud a los peticionarios de aguas superficiales y subterráneas.

Por último, importante es el hecho de que la presentación de las solicitudes se contará desde que se haya otorgado el permiso para explorar aguas subterráneas. Como resultado de ello, se intenta impedir que una persona distinta del explorador espere los resultados de las exploraciones (las que tienen un importante costo) y solicite el aprovechamiento de las aguas del mismo acuífero sin haber hecho gasto alguno en faenas de exploración (artículo 58 inciso tercero nuevo).

\section{PREFERENCIA EN EL OTORGAMiento DEL DERECHO DE AGUAS SUBTERRÁNEAS (ARTÍ́CULO 58 BIS NUEVO)}

Este nuevo se intercala a continuación del artículo 58. Dice así:

"Artículo 58 bis.- Comprobada la existencia de aguas subterráneas en bienes nacionales, el beneficiario del permiso de exploración tendrá la preferencia para que se le otorgue el derecho sobre las aguas alumbradas durante la vigencia del mismo por sobre todo otro peticionario, salvo que otro solicitante, dentro del plazo que señala el inciso primero del artículo 142 de este Código, baya presentado una solicitud para constituir un derecho de aprovechamiento sobre las mismas aguas que se alumbraron y solicitaron durante la vigencia del período de exploración, en cuyo caso, y si no existe disponibilidad para constituir ambos derechos, se aplicarán las normas sobre remate señaladas en los artículos 142, 143 y 144. Esta excepción no será aplicable si el permiso para explorar aguas subterráneas fue adquirido de conformidad con lo dispuesto en el inciso segundo del artículo anterior.

La preferencia consagrada en el inciso anterior, solo podrá ejercerse dentro del plazo del permiso, y hasta tres meses después, y siempre que el concesionario baya dado cumplimiento a la obligación de presentar un informe completo sobre los trabajos realizados, sus resultados y las conclusiones obtenidas".

4 La doctrina señala que la igualdad "en" la ley, asegura "un conjunto de deberes, derechos y garantías del ordenamiento jurídico. Esto se refiere, entonces, a que el contenido de las leyes sea igual para todos, o desigual si así corresponde, sobre la base o en función, exclusivamente, de la justicia". Céa Egaña, José Luis (2004) Derecho Constitucional Chileno. Derechos, Deberes y Garantías. Tomo II. Santiago: Ediciones Universidad Católica de Chile, p. 128. 
Esta nueva disposición no viene más que a complementar y hacer operativa la norma del artículo 58 referida al remate. Así, lo que se consagra por medio de este artículo es la preferencia del titular del permiso de poder explorar para que se le constituya dentro del área de exploración, un derecho de aprovechamiento sobre las aguas subterráneas alumbradas durante la vigencia de este. Esta preferencia tiene una excepción y una contraexcepción. La excepción está dada por el hecho de que si otra persona solicita un derecho de aprovechamiento de aguas en un mismo acuífero dentro del plazo de seis meses, y no existe agua para ambas solicitudes, la situación se resuelve mediante remate. Este remate no se aplicará (contraexcepción) si el titular de la exploración adquirió este permiso mediante dicho título, en cuyo caso se mantiene la preferencia a todo evento.

Sin embargo, la preferencia consagrada anteriormente solo podrá ejercerse dentro del plazo del permiso, y hasta tres meses después, y siempre que el concesionario haya cumplido la obligación de presentar un informe completo sobre los trabajos realizados, sus resultados y las conclusiones obtenidas. Es decir, se obliga al concesionario a justificar su preferencia mediante la ejecución de trabajos que ameriten la preferencia otorgada mediante una obligación de hacer. Para ello, será indispensable presentar un informe acreditando los trabajos hechos, sus resultados y las conclusiones obtenidas luego de haber explorado el terreno. De esta manera, esta reforma va en la línea de asegurar que quienes obtengan la preferencia, acrediten fehacientemente su intención decidida de realizar las exploraciones a que se obligaron, siendo el informe que deben acompañar una especie de "amparo" por el trabajo realizado, mecanismo que permite a la DGA asegurar que los trabajos fueron efectiva y debidamente hechos.

El plazo de tres meses desde el permiso para ejercer dicha preferencia parece prudente, entendiendo que son seis meses los que se tienen, en función del artículo 58 inciso segundo, para ser parte del remate. Sin embargo, nada dice el nuevo artículo 58 bis en caso de que no se ejerza la preferencia dentro del plazo del permiso o de los próximos tres meses, o que habiendo ejercido esa preferencia no se presente el informe que ordena la ley.

A nuestro juicio, de ocurrir la situación descrita, creemos que operaría una condición resolutoria ordinaria ${ }^{5}$, es decir, la preferencia obtenida será un derecho destinado a extinguirse si no se cumple, ya sea con el

Esta es definida "como el acontecimiento futuro e incierto del cual depende la extinción de un derecho, siempre que dicho acontecimiento no constituya el incumplimiento de una obligación pues, en tal caso, nos encontraríamos en presencia de otra especie de condición resolutoria". VIAL Del Rfo, Víctor (2000) Acto Jurídico y Personas. Teoría General del Acto Jurídico. Santiago: Ediciones Universidad Católica de Chile, p. 224. 
ejercicio de dicha preferencia o con la entrega del informe, sin perjuicio de que quien obtenga la preferencia pueda ceder dicho derecho a otro interesado.

En consecuencia, al no ejercerse este derecho, podría, como mecanismo alternativo, procederse a un remate de los derechos de la preferencia que no se ejerció. De aceptarse esta postura, podrán participar todos aquellos que tengan solicitudes superpuestas, y que estas, además, recaigan sobre la extensión del terreno franco en cuestión. No parece haber inconveniente para que la extinción de la preferencia sea solicitada a petición de parte o de oficio por parte de la DGA.

\section{ASPECTOS ADMINISTRATIVOS QUE COMPLEMENTAN LAS REFORMAS A LOS ARTÍCULOS 58 INCISOS SEGUNDO Y TERCERO Y 58 BIS}

Al producirse la modificación al Código de Aguas, la Resolución $\mathrm{N}^{\circ} 186$ de 1996 de la DGA siguió vigente, pero solo hasta 16 de noviembre de 2005, fecha en que comenzó a regir la nueva Resolución modificada, la $\mathrm{N}^{\circ} 341$ de 2005 (en adelante la Resolución), todo ello, con el objeto de ajustarla a la nueva normativa legal.

El artículo $7^{\circ}$ es el único artículo de la Resolución que detalla ciertos aspectos del remate. Este prescribe lo siguiente:

"Si de acuerdo con lo consignado en el artículo 58 del Código de Aguas, se presentaran dos o mas solicitudes de exploración de aguas subterráneas en una misma extensión territorial de bienes nacionales, dentro del plazo de seis meses contados desde la primera presentación, se resolverá la adjudicación del área superpuesta, sea esta total o parcial, mediante remate entre los solicitantes que se encuentren en esta situación.

El área a rematar corresponderá a la extensión superpuesta, y habrá tantas áreas a rematar como superposiciones existan.

Las bases del remate se establecerán por resolución del Director General de Aguas.

La Dirección General de Aguas podrá autorizar la exploración en la superficie no afecta a remate o superficies parciales adquiridas a través de remate, siempre y cuando el peticionario adecue para ello los antecedentes exigidos en los artículos 4 y 5 de la presente resolución".

Por medio de esta norma se aclara una duda razonable al especificarse, de manera concreta, la superficie que, en caso de existir superposiciones, será objeto de remate. Es decir, la norma alude a aquella franja de terreno que se encuentra superpuesta ya sea por dos o más solicitudes idénticas, o por dos o más solicitudes diferentes, pero que tienen una franja de terreno en común.

Respecto de las bases, las cuales establecerá la DGA, parece adecuado que sea ella la que las fije. Sin embargo, se advierte lo deficiente de 
que las normas referidas al procedimiento de remate no tengan en su totalidad fuente legal, lo que abre espacios no deseados para una posible discrecionalidad de la autoridad.

Si bien los artículos 58 y 58 bis del Código de Aguas remiten la regulación del remate a los artículos 142, 143 y 144 del Código de Aguas en lo que corresponda, el mismo artículo $7^{\circ}$ de la Resolución demuestra que la regulación de dichos artículos no es suficiente, demostrando, una vez más, que lamentablemente la intervención administrativa es necesaria para regular este tipo de procedimientos, pues el legislador no reguló de manera precisa y detallada el procedimiento de remate, lo que atenta contra el artículo $19 \mathrm{~N}^{\circ} 3$ inciso $5^{\circ}$ de la Constitución, pues todo órgano que ejerza jurisdicción, es decir, que "diga el derecho" aplicable al caso concreto, tal como lo es al adjudicar un derecho mediante un remate, debe fundarse en un proceso previo legalmente tramitado, correspondiendo siempre y sin excepciones al legislador establecer un justo y racional procedimiento. Las excepciones a este principio están total y debidamente excluidas de cualquier justo y racional procedimiento, tal como debe ser el de remate, estando el artículo séptimo de la Resolución en contradicción con ello. Asimismo, siguiendo la misma línea argumental, se atenta, también, contra el principio de la reserva legal de los procedimientos administrativos contemplada en el artículo $63 \mathrm{~N}^{\circ} 18$, el que señala que son materias de ley "las que fijen las bases de los procedimientos que rigen los actos de la administración pública", situación que en el caso que comentamos no acontece con la rigurosidad merecida. Este es una asunto de reserva legal fuerte o indelegable, tal como to ha entendido la doctrina y la jurisprudencia ${ }^{6}$.

Por último, es importante destacar que la DGA podrá (sujeta a discreción), si los antecedentes lo permiten, autorizar la exploración en la superficie no afecta a remate o superficies parciales adquiridas a través de remate, siempre y cuando el peticionario adecue para ello los antecedentes exigidos en los artículos $4^{\circ}$ y $5^{\circ}$ de la Resolución 7 .

6 PALAcios GonZÁlez, Galvarino (1987) "La Garantía Constitucional del Racional y Justo Proceso", Gaceta Jurídica N 84. El T. Constitucional, con fecha 18 de junio de 1991, Rol 124 , señaló que "(...) las normas del proceso legal previo que contempla el inciso $5^{\circ}$ del articulo $19 \mathrm{~N}^{\circ} 3$ de la Carta Fundamental, en aquellos casos en que no existe disposición legal expresa sobre la materia, no pueden tener plena aplicación respecto de los actos administrativos mientras no se dicte la legislación que prevé el artículo $60 \mathrm{~N}^{\circ} 18$ de la Constitución". Considerando $8^{\circ}$. En http // www.tribunalconstitucional.cl [consulta: 2 de septiembre de 2007].

Artículo $4^{\circ}$ : "La solicitud de exploración deberá contener: a) La ubicación de los terrenos que se desea explorar, para lo cual deberá individualizarse la comuna en que ellos se encuentran. En caso que comprenda una o más comunas deberán indicarse todas ellas. b) La extensión aproximada de los terrenos que se desea explorar y su delimitación precisa a través de las coordenadas de los vértices de la poligonal que la definen. Dichas coordenadas deberán expresarse en el sistema U.T.M., obtenidas de la cartografía oficial del Instituto Geográfico Militar, señalando la escala y el datum 


\section{DECLARACIÓN DE PROHIBICIÓN Y COMUNIDAD DE AGUAS (ARTículo 63)}

El artículo 63 contempla la posibilidad de que la DGA declare zonas de prohibición "para nuevas explotaciones, mediante resolución fundada en la protección del acuífero, la cual se publicará en el Diario Oficial". Esta decisión debe fundarse en el hecho de que el acuífero se encuentre ante una sobreexplotación comprobada, la que una vez determinada -previa petición de parte o de oficio por la DGA-, autorice a este organismo a declararla, impidiendo que nuevos peticionarios puedan explotarlo. El objetivo de esta medida es, entre otros, proteger al acuífero ante su extinción futura; evitar la contaminación que pudiera experimentar -ya sea por agentes naturales o humanos-; proteger los derechos de aprovechamiento sobre aguas superficiales, debido a la unidad y conectividad que ambos tipos de agua tienen; y finalmente, el no constituir nuevos derechos para no continuar la sobreexplotación del acuífero. Por supuesto, los derechos constituidos con anterioridad a la declaración no se verán afectados por esta medida, pues lo que se prohíbe es la constitución de nuevos derechos sobre un determinado acuífero. Pues bien, por medio de la reforma al artículo 63 se añadió el siguiente inciso segundo:

"La declaración de una zona de probibición dará origen a una comunidad de aguas formada por todos los usuarios de aguas subterráneas comprendidos en ella".

Por medio de esta reforma se hace extensiva la institución de las comunidades de aguas, las que se forman por el solo ministerio de la ley en el caso de la declaración de áreas de restricción, a las zonas de prohibición. De esta

utilizado. Además, se podrá hacer referencia a puntos conocidos tales como, ciudades, pueblos, caminos públicos, cauces, cerros, etc., que permitan ilustrar acerca del sector que se solicita explorar. c) Aquellas solicitudes destinadas a explorar en bienes nacionales de forma compleja, tales como cauces naturales, calles, plaza "otros, deberán identificarlos explícitamente. La delimitación se efectuara mediante un polígono que los incluya, y la extensión de los terrenos estará referida a dicho poligono. d) El nombre completo o razón social y el RUT del solicitante. Las solicitudes que no cumplan con los requisitos establecidos precedentemente o que contengan menciones erróneas, serán denegadas de plano".

Artículo $5^{\circ}$ : "El peticionario, al momento de presentar la solicitud deberá acompañar los siguientes antecedentes: a) Una memoria técnica explicativa que indicará los estudios, y las cantidades de obras de exploración que se pretenden realizar, expresadas en número de pozos, metros de perforación, número de perfiles geofísicos, etc. b) Un cronograma de actividades de exploración, que incluirá la fecha de inicio y término de cada una de ellas. c) Un plano a escala del área de exploración con los antecedentes solicitados en la letra b) del artículo anterior, que contenga las coordenadas de los puntos que definen el área. d) Un informe de las medidas y previsiones adoptadas para el debido resguardo del entorno ecológico y la protección de los acuiferos durante las labores de exploración. e) Si la solicitud recayere sobre bienes fiscales cuya tenencia baya entregado el Estado a cualquier título a personas naturales o jurídicas, deberá obtener la autorización de estas. $f$ Si la solicitud recayere en algunas de las áreas indicadas en el artículo 13 de la presente resolución, se deberá acompañar la resolución favorable de calificación ambiental. Las solicitudes de exploración que no den cumplimiento, ya sea total o parcialmente, a la exigencia establecida en inciso precedente, serán denegadas de plano". 
manera, se utiliza un mecanismo eficiente desde el punto de vista de la gestión de los recursos hídricos, pues se otorga a los particulares-quienes son los más que ainteresados en cuidar las aguas- el control de estas.

Al analizar este cambio, comprobamos que el artículo 186 del Código de Aguas ya reconoce esta situación, pues prescribe que "Si dos a más personas tienen derechos de aprovechamiento en las aguas de un mismo canal, embalse, o aprovechen las aguas de un mismo acuífero, podrán reglamentar la comunidad que existe como consecuencia de este becho...". Por lo tanto, la reforma a este artículo no viene más que a consolidar una situación ya existente.

Pese a la repetición en que incurre la norma en términos genéricos, se advierte que la modificación que se analiza avala y sienta un peligroso precedente en orden a consolidar una comunidad de aguas no por el solo ministerio de la ley, sino que por una resolución administrativa, pues al declarar la DGA un área de prohibición en un acuífero (por acto administrativo), se da origen a la respectiva comunidad, cuestión que como se comprueba de la sola lectura del artículo 186, esta ya ha sido formada.

En otras palabras, se autoriza peligrosamente a la DGA para que por vía administrativa, en caso de así estimarlo, junto con la ley formen una comunidad de usuarios respecto de las aguas del acuífero, operando la ley como un mecanismo de "pantalla" para validar tal decisión.

No debe olvidarse que la Constitución reconoce el derecho a asociarse (19 $\left.\mathrm{N}^{\circ} 15\right)$, el que en forma clarísima en su inciso tercero reconoce que "nadie puede ser obligado a pertenecer a una asociación". Pese al tenor y al espíritu de esta norma, mediante el nuevo inciso incorporado al artículo 63 del Código de Aguas, se transgrede la garantía a la libre asociación, ya que nadie puede ser obligado a pertenecer a una, teniendo como uno de sus caracteres fundantes una mera resolución administrativa. Cabe insistir en la idea ya expresada en el sentido de que el propio TC ha reconocido a este derecho como la libertad que "consiste precisamente en el poder de autodeterminarse en cuanto pertenecer o no, crear o no, una sociedad, asociación o grupo corporativo específico, vale decir, no ser coaccionado a integrarse a un determinado ente societario; acoger o no, libremente, como miembro a un determinado sujeto que deseare integrarse a él; en fin retirarse o no de ese grupo o cuerpo asociativo libremente" 8 .

Por lo tanto, al consolidarse una comunidad por el solo ministerio de la ley, debido no a la ocurrencia de una hecho, sino a la dictación de una resolución administrativa, se está, también, formando por vía discrecional una asociación, lo que contradice el principio de la reserva legal y de la libre asociación, pues se obliga a formar una comunidad con los restantes usuarios, no solo por mandato legal -el que de haber existido demostraría, al menos, una prudente conciencia constitucional-, sino que 
también por vía administrativa, lo que repugna a un serio intérprete constitucional, pues la autonomía de la voluntad -pilar básico de nuestro derecho público y privado- se ve fuertemente disminuida por una simple resolución de un ente de la administración que le da, entre otros, el carácter fundante a una agrupación forzada. Solo la ley, y no junto con una norma de inferior jerarquía, debe determinar precisamente qué circunstancias dan origen a este tipo asociaciones.

\section{ASPECTOS ADMINISTRATIVOS QUE COMPLEMENTAN LA REFORMA AL ARTí́CUlo 63 DEL Código de AGUAS}

El artículo 36 nuevo de la mencionada Resolución señala que la DGA declarará zona de prohibición para nuevas explotaciones cuando se hayan constatado alguna de las siguientes situaciones:

a) Que los descensos generalizados provoquen el agotamiento de algunas zonas del acuífero, imposibilitando la extracción de aguas subterráneas de derechos de aprovechamiento existentes en dichas zonas.

Esta causal se refiere al hecho de que cuando los descensos generalizados de agua en el acuífero se hayan manifestado a lo largo y ancho de este, provocando o determinando el agotamiento de al menos dos o más zonas de este, y trayendo como consecuencia la imposibilidad de extraer aguas de dichas zonas, se podrá solicitar (a petición de parte) o declarar (de oficio) por parte de la DGA la prohibición para constituir nuevas explotaciones sobre dicho acuífero.

Debiera a futuro aclararse con mayor precisión esta causal, pues da espacios importantes para una discrecionalidad, que por vía administrativa no trata de limitar un derecho fundamental (desarrollo de actividades económicas y derecho de propiedad), sino de prohibirlo, lo que es aún más grave. Por ejemplo, qué se entiende por "descensos generalizados", debe ser un asunto que la DGA a futuro deberá precisar.

b) Que la recarga del acuífero sea superada, produciendo descensos sostenidos de sus niveles, al grado que provoque reducciones superiores al cinco por ciento del volumen almacenado en un plazo de cincuenta años.

Por su parte, la segunda causal alude a que procederá la prohibición una vez que la recarga sea superada (cuando la demanda por agua sea superior a la oferta o ingreso de esta al acuífero), esto es, una vez producidos los descensos sostenidos en los niveles de acuífero.

Es decir, los descensos producto de la falta de recarga deben ser sostenidos en el tiempo, al grado que generen un efecto, pues los descen- 
sos sostenidos puramente no son causal suficiente, pues debe producirse una segunda consecuencia: una reducción superior al cinco por ciento del volumen almacenado en un plazo de cincuenta años. En otras palabras, la sobreexplotación de un acuífero estará determinada por ambos factores.

Si bien esta causal es más precisa que la anterior, lo que evita grados importantes de discrecionalidad al establecer un porcentaje tolerable de disminución de los niveles de almacenamiento (no superior al $5 \%$ ), es de esperar que los medios materiales (económicos y administrativos) y humanos con que cuenta la DGA hagan realizable la aplicación de esta norma.

c) Que se produzca afección a los caudales de los cursos de aguas superficiales y vertientes en más de un diez por ciento del caudal medio de estiaje, afectando derechos de aprovechamiento existentes.

Esta causal es coherente con la disciplina del derecho de aguas, pues se toma en cuenta el principio de la unidad de la corriente o de la cuenca hidrográfica, ya reconocido jurisprudencialmente? , para prohibir o no nuevas explotaciones.

Así, la realidad que estén viviendo las aguas superficiales, ya sea de escasez o de abundancia, es determinante para finalmente decidir si se declara o no una zona de prohibición respecto de las aguas subterráneas, cuya conectividad y unidad con las aguas superficiales es indispensable. Sin embargo, la norma señala de manera expresa que son las aguas superficiales y las vertientes las que deben haber reducido su caudal medio en período de estiaje (nivel más bajo o caudal mínimo) en más de un diez por ciento, debiendo afectar, además, los derechos de aprovechamiento existentes para que dicha medida sea tomada, medida que parece razonable.

d) Que exista contaminación del acuífero por desplazamiento de aguas contaminadas o de la interfase agua dulce-salada en sectores próximos a aguas salobres, comprometiendo las captaciones existentes.

Esta penúltima letra aborda un problema distinto de los anteriores (escasez de agua del acuífero), pues contempla la posibilidad de que el acuífero, por desplazamiento de aguas contaminadas, no importando su origen (natural o humano), y por la interfase de agua dulce-salada, sea afectado, perjudicando las captaciones existentes en él.

9 Destaca desde hace más de cien años aquella sentencia que reconoce que "No puede sostenerse como principio general que un río y su afluente sean dos entidades distintas que no tengan relación entre sí, puesto que los afluentes son los que contribuyen a formar el caudal de aguas del río" (RDJ., Tomo 2, 1, p. 126). Vergara Blanco, Alejandro (1998) Derecho de Aguas. Tomo I. Santiago: Editorial Jurídica de Chile, p. 245. 
Interesante es destacar el concepto amplio de contaminación que contempla esta letra, pues de manera correcta considera la posibilidad de la intrusión marina, esto es, el ingreso de agua salada a un acuífero, lo cual genera enormes dificultades, pues la densidad, la viscosidad y a veces la temperatura son diferentes. Esto muchas veces, si no es detectado a tiempo, destruye e inutiliza los acuíferos. Consideramos de esta manera acertada esta causal, ya que contempla de manera amplia la posibilidad de que el acuífero sea contaminado ${ }^{10}$.

\section{e) Que exista afección al medio ambiente en los sectores protegidos indicados en el artículo 22 letra $f$ ) de la presente resolución.}

Por último, esta causal, también referida a la contaminación de un acuífero, señala que cuando sean afectados los sectores protegidos indicados en el artículo 22 letra f) de la presente resolución, estas son: 1) las zonas que alimentan áreas de vegas y de los llamados bofedales de las regiones de Tarapacá y de Antofagasta, previamente identificadas y delimitadas por la DGA; 2) las áreas protegidas correspondientes a alguna de las unidades o categorías de manejo que integran el Sistema Nacional de Áreas Silvestres Protegidas por el Estado; 3) los Humedales inscritos o reconocidos en el listado de Humedales de Importancia Internacional de la Convención Ramsar; y 4) cualquiera otra área que se encuentre bajo protección oficial de acuerdo a lo establecido en el artículo 10 letra p) de la Ley 19.300 , procederá la declaración que prohíba constituir nuevos derechos para explotar un acuífero.

De las causales ya enumeradas, destaca el hecho de que se abordan los dos grandes problemas que enfrenta un acuífero (la falta de recarga y su contaminación). Todas las causales, además, son nuevas, pues ninguna de las actuales era contemplada en la Resolución $N^{\circ} 186$ de 1996 de la DGA. Valoramos así, el hecho de que la DGA precise de manera más expresa las causales mediante las cuales se puede declarar la prohibición de un acuífero, disminuyendo así grados importantes de discrecionalidad. Pese a eso, advertimos el hecho, hasta ahora no resuelto, de que se establezcan prohibiciones de carácter administrativo para la realización de actividades económicas (artículo $19 \mathrm{~N}^{\circ} 21$ de la Constitución) ${ }^{11}$, lo que atenta contra el espíritu de la Constitución.

10 Para una comprensión precisa acerca de este fenómeno: WHITTOW, John (1988) Diccionario de Geografía Física. Madrid: Alianza Editorial; y Custodio, Emilio (1976) Hidrología Subterránea. Barcelona: Editorial Omega,

I1 Si bien la postura contraria cuenta con un sólido respaldo doctrinal [BULNES ALDUNATE, Luz (1985) "El derecho a desarrollar cualquier actividad económica". Revista de Derecho Público, $\mathrm{N}^{\circ} 37-38$, pp. 149-165], no parece sensato, siguiendo una interpretación armónica y finalista del texto constitucional, pese a que este no da una respuesta certera 
Junto a lo anterior, advertimos que otorgarle competencias ambientales a la DGA desnaturaliza el principio mediante el cual la ley 19.300 entregó la coordinación de todas las políticas ambientales a la CONAMA, potestad que, a parte de descoordinar al sector público y como contrapartida confundir al ciudadano, prohíbe el ejercicio de un derecho.

Se debe recordar que es ella, la propia DGA, la que determina la prohibición o el alzamiento de la medida, por lo que es ella quién debe hacer los estudios ambientales respectivos, lo que desnaturaliza completamente la idea que originalmente tuvo la ley $19.300^{12}$.

Respecto a la duración y término de esta medida, debemos decir que está determinada por el hecho de que se solicite, de manera justificada a petición de parte el alzamiento de la medida, siempre que así lo aconsejen los resultados de nuevas investigaciones respecto de las características del acuífero o la recarga artificial del mismo. Una vez presentados estos antecedentes, la DGA deberá pronunciarse acerca de la medida, ya sea, manteniéndola o alzándola, todo ello en conformidad al artículo 131 y siguientes del Código de Aguas.

\section{DECLARACIÓN DE OFICIO DE LA DGA EN LA DETERMINACIÓN DE UNA ZONA DE RESTRICCIÓN (ARTÍ́CULO 65)}

El artículo 65 del Código de Aguas trata acerca de la declaración de área de restricción de un acuífero, la que constituye una medida preventiva, previa a la declaración de prohibición, la cual tiene por objeto la protección de este cuando exista riesgo de sobreexplotación.

respecto a si es el legislador o la administración la que está facultada para prohibir una actividad económica, que una norma de rango administrativo pueda, concordando con Fermandois "(...), ni siquiera si la ley así lo faculta, prohibir por sí una actividad económica determinada; el administrador solo está autorizado para aplicar los parámetros establecidos en la ley, la que, por ser general, especialmente en esta materia, suelen ser insuficientes para identificar una actividad económica específica y decretar su prohibición", siendo en definitiva "quien está llamado primeramente a imponer una eventual prohibición de alguna actividad económica, atentatoria contra la moral, el orden público y la seguridad nacional, es el juez, por vía represiva". FERMANDOIS VÖHRINGER, Arturo (2006) Derecho Constitucional Económico. Garantias económicas, doctrina y jurisprudencia. Tomo I. Santiago: Ediciones Universidad Católica de Chile, p. 145 y p. 147.

12 Similar situación ocurrió con la exigencia de un estudio de impacto ambiental por parte del Ministerio de Bienes Nacionales; sentencia de la Corte de Apelaciones de Antofagasta, de 23 de noviembre de 2000. RDJ., Tomo 98, sec. $7^{\mathrm{a}}$. p. 45. Asimismo, y siguiendo en la línea que comentamos, la reforma agregó un nuevo título al Código de Aguas titulado "De la Proteción de las aguas y cauces", en que a la DGA se le entregaron facultades por medio del artículo 129 bis 1 para "velar por la preservación de la naturaleza y la protección del medio ambiente, debiendo para ello -al constituir derechos-establecer un caudal ecológico minimo (...)". 
Por medio de la reforma que comentamos, fue introducida una nueva modalidad respecto de los que tienen legitimación activa para poder solicitar la declaración de una zona de restricción. Antes solo podía ser declarada por la DGA, siempre que fuese a petición de parte. Hoy, la situación es diferente, ya que por medio de la reforma de junio de 2005 , se otorga a la DGA la posibilidad para que declare de oficio como área de restricción un acuífero determinado. Dice así el nuevo inciso segundo del artículo 65:

"Cuando los antecedentes sobre explotación del acuifero demuestren la conveniencia de declarar área de restricción de conformidad con lo dispuesto en el inciso anterior, la Dirección General de Aguas deberá así decretarlo. Esta medida también podrá ser declarada a petición de cualquier usuario del respectivo sector, si concurren las circunstancias que lo ameriten".

Parecía una contradicción que la DGA pudiese tomar una decisión de oficio respecto de un asunto cuyas consecuencia jurídicas eran más intensas y drásticas (prohibición); y por otra, no pudiese, mediante el mismo mecanismo (de oficio), declarar una zona de restricción, medida intensamente menor y cuyas consecuencias jurídicas futuras son menos severas. Así, lo que se pretendía era circunscribir o delimitar la facultad de la DGA para declarar un área de restricción de manera de evitar que dicha atribución sea utilizada de manera genérica. Pese a dicho espíritu, el resultado obtenido es inversamente contrario, pues es precisamente esta modificación legal la que de mayor forma extiende la discrecionalidad administrativa, ya que en ningún caso, como lo pretendió el Ejecutivo, se circunscribe o delimita esta facultad; por el contrario, crece de manera desmedida alcanzando ribetes que a futuro se desconocen, pues lo que hace la DGA es restringir ${ }^{13}$ un derecho (libertad económica y propiedad) sin contrapeso alguno. Reconocemos, eso sí, que al menos aclara el panorama respecto de que a partir de ahora la DGA tendrá esta facultad, lo que permite terminar con la confusión respecto a si dicho organismo tenía esta potestad. A partir de ahora, la duda ha sido zanjada.

Sin embargo, lo grave de esta disposición es que se le otorga una facultad a la DGA que puede, en caso que no sea utilizada correctamente, abrir espacios para una futura discrecionalidad, lo que reduce, de manera importante, la seguridad y la estabilidad de los derechos constituidos y por constituir (provisorios). Por eso, esta facultad no puede permanecer entregada a la sola voluntad de la autoridad, teniendo como único límite legal para la declaración de una zona de restricción de un acuífero, el

13 Debe recordarse que el artículo 12 de la Ley Orgánica de Estados de Excepción Constitucional prescribe que se "restringe una garantía constitucional cuando, durante la vigencia de un estado de excepción, se limita su ejercicio en el fondo o en la forma", cuestión que en el caso que analizamos es evidente. 
estudio de los "antecedentes de explotación" del acuífero que "demuestren su conveniencia", más aún cuando su restante limitación está dada por el artículo 31 de la Resolución, la que señala los efectos que deben producirse para que la DGA esté autorizada para tomar esta medida. Como se ve, su límite restante es de carácter administrativo, es decir, es la propia DGA la que establece los parámetros de su propia limitación, pudiendo ella en cualquier momento decidir cuándo es necesario y posible cambiar, modificar, alterar o suprimir las causales-efectos necesarios para adoptar esta medida. En otras palabras, los motivos por los cuales se decide esta medida, son fijados por la propia administración, quedando los particulares en la más absoluta desprotección, pues la regulación legal es excesivamente genérica y vaga.

Esto atenta claramente contra la certeza y seguridad a que debe aspirar todo ordenamiento jurídico, y en especial, la disciplina del derecho de aguas, la que por su trascendencia dentro del ordenamiento jurídico y económico debe aspirar a niveles de mayor certeza.

Por tanto, debe ser siempre la ley y no una norma de inferior jerarquía la que deberá señalar cuándo, bajo qué circunstancias y qué derechos se podrán afectar en caso que se declare una zona de restricción, y no, tal como ocurre, por medio de una resolución de carácter administrativo. Cabe destacar que la propia DGA ha demostrado la mutabilidad de la Resolución $\mathrm{N}^{\circ} 341$, pues esta ha sido reformada en tres ocasiones. Lo que se plantea no es extraño a nuestra jurisdicción constitucional, ya que esta ha reconocido que "la potestad reglamentaria, puede ser convocada por el legislador o ejercida por el Presidente de la República, nada más que para reglar cuestiones de detalle, de relevancia secundaria o adjetiva, cercanas a situaciones casuísticas o cambiantes, respecto de todas las cuales la generalidad, abstracción, carácter innovador y básico de la ley impiden o vuelven difícil regular"14, situación que en la regulación que comentamos no ocurre, pues asuntos de carácter esencial y no "secundarios" (como lo son las causales para declarar una zona de restricción) son reguladas por medio de una reglamentación administrativa. Es la ley, en función del principio de reserva legal, la que debe regular de manera precisa y no mediante enunciados genéricos estas circunstancias. Así, lo que ha faltado por medio de la reforma, todo ello con el objeto de evitar la discrecionalidad de la que hacemos referencia, es una mayor densidad normativa por parte del legislador, puesto que debió haber regulado con mayor precisión y detalle aspectos (centrales) que abandonó a la autoridad administrativa (como lo es lo medular de una declaración de una zona de restricción), no debiendo haberlo hecho, pues finalmente lo que ha realizado no es más que "una babilitación ex-

14 Sentencia del T. Constitucional, de 9 de abril de 2003, Rol 370, Considerando trigésimo cuarto. En http://www.tribunalconstitucional.cl consulta: [21 de marzo de 2007]. 
cesiva a favor de la potestad reglamentaria de ejecución o, más grave aún, a raíz de tratarse de una deslegalización, siempre contraria a la Carta Fundamental por hallarse en ella probibida"15. Nuestra postura no consiste en que el Código de Aguas abandone su carácter general y abstracto, y que en consecuencia la ley regule hasta el más mínimo detalle, abandonando así el dominio máximo legal consagrado en nuestra Constitución, sino que las remisiones que esta haga a la potestad reglamentaria señalen de manera precisa el derecho que pueda afectarse y de qué manera este será tratado. En otras palabras, que respete la relación entre medios y fines, propia por lo demás, de un juicio acertado de racionalidad.

Para ello, la ley debió haber cumplido con "los requisitos de 'determinación' y 'especificidad'. El primero exige que los derechos que pueden ser afectados, se señalen, de manera concreta, en la norma legal; y el segundo requiere que la misma indique, de manera precisa, las medidas especiales que se puedan adoptar con tal finalidad. Por último, los derechos no podrán ser afectados en su esencia, ni imponerles condiciones, tributos o requisitos que impidan su libre ejercicio. Cumplidas que sean dichas exigencias, es posible y lícito que el Poder Ejecutivo haga uso de su potestad reglamentaria de ejecución, pormenorizando y particularizando, en los aspectos instrumentales, la norma para bacer asi posible el mandato legal"16.

Aquí es precisamente donde recae la inconstitucionalidad de la norma del inciso segundo del artículo 65 del Código de Aguas: no basta con que la ley faculte a la DGA para declarar de oficio una zona de restricción, deberá además, señalarse, en dicha norma legal, los derechos que se afectan (el desarrollo de actividades económicas, $19 \mathrm{~N}^{\circ} 21$; y el derecho de propiedad, $19 \mathrm{~N}^{\circ} 24$ de la Constitución) y las medidas especiales (zona de restricción, que sí están en la ley) que se pueden adoptar con tal finalidad, lo que incluye, obviamente, las causales por la cuales se podrá declarar dicha medida (todas ellas, lamentablemente, en el artículo 31 de la Resolución $\mathrm{N}^{\circ} 341$ de 2005 de la DGA). Al no cumplirse con la reserva legal poderosa que ambos derechos descritos exigen al ser regulados, se afecta gravemente la vigencia de ellos, erosionando aquellas áreas de libertad y propiedad que precisamente la reserva legal intenta proteger $^{17}$.

En consecuencia, escapa a toda lógica de justicia y confianza legítima de las personas en la administración el hecho de que ella por medio de un acto administrativo y no por medio de la ley, defina cuándo es posible y bajo qué circunstancias declarar una zona de restricción. Hoy,

\footnotetext{
15 Sentencia del T, Constitucional (15). Considerando trigésimo quinto.

16 Sentencia del T. Constitucional, de 26 de junio de 2001, Rol 325. Considerando cuadragésimo. En http://www.tribunalconstitucional.cl [consulta: 21 de marzo de 2007].

17 Zapata Larraín, Patricio (1994) La jurisprudencia del Tribunal Constitucional. Santiago: Corporación Tiempo 2000, p. 193.
} 
podrán ser determinadas causales, mañana podrán ser otras. Al regularse derechos fundamentales, el vehículo idóneo para ello es la ley, y no un acto administrativo que en la especie ha adoptado el carácter de resolución. Al menos, las causales por la cuales la DGA puede declarar una zona de restricción deben estar en la ley y eso precisamente no ocurre, lo que atenta contra el riguroso principio de la reserva legal ya comentado. La idea es que cualquier decisión administrativa este impregnada por los principios de razonabilidad y objetividad, los cuales limiten los parámetros de acción de la administración. Al fijar ella (la administración) los motivos por los cuales puede declararse una zona de restricción, se hace probable el evadir los principios ya indicados y la propia ley, siendo esta última la llamada a formular la medida que se podrá adoptar en contra de uno u otro derecho.

El hecho que la ley no contemple las causales por las cuales puede adoptarse esta decisión, no se aprecia que haya un motivo que justifique la adopción de este acto administrativo, pues la remisión legal en los términos que ha sido planteada, sigue siendo vaga y general, no contando con la precisión (señalamiento de las causales, efectos o motivos) que permitan dar validez jurídica a la adopción del acto de la autoridad ${ }^{18}$.

En conclusión, al no regular la ley los motivos, causales o efectos que deben producirse en un acuífero para declarar una zona de restricción, el precepto legal aludido (artículo 65) no cumple con lo preceptuado por la Constitución, ni con los criterios de determinación y especificidad que exige la jurisprudencia del tribunal constitucional para regular o complementar derechos fundamentales (19 $\mathrm{N}^{\circ} 21$ y 24). De esta forma, se le entrega a la DGA, mediante una remisión legislativa amplia, la más extensa y general facultad para poder determinar ella, de la manera que lo estime, los hechos (principio de tipicidad) constitutivos para declarar una zona de restricción, no sujetándose a ningún autocontrol consistente.

\section{RECARGA ARTIFICIAL DE ACUÍfEROS (ARTículo 66)}

Por su parte, el artículo 66 también sufrió cambios, ya que su inciso segundo fue modificado de la siguiente forma:

\footnotetext{
18 El tema de la reserva legal no es pacífico, al menos la jurisprudencia del $\mathrm{T}$. Constitucional así lo demuestra, pues este ha reconocido en una primera etapa una reserva legal "absoluta" de ley al regular diversos derechos, tal como los demuestran los paradigmáticos casos de "Publicidad Caminera I y II" (rol 146 y 167), "Playas" (245-246), "Ley de Bases del Medio Ambiente" (rol 185), "Ley de Aduanas" (rol 247) e "Impacto Vial" (rol 370 ). Por otra parte, ha reconocido una reserva legal "relativa" en otros innumerables fallos, tales como "Cesiones Gratuitas de Terrenos" (rol 253), "Ley de Presupuesto" (rol 254), "Acuerdo de complementación con Bolivia" (rol 282), por lo que reconocemos la legítima discusión en torno a este concepto.
} 
"Sin perjuicio de lo establecido en el inciso primero del artículo 67, y no siendo necesario que anteriormente se haya declarado área de restricción, previa autorización de la Dirección General de Aguas, cualquier persona podrá ejecutar obras para la recarga artificial de acuíferos, teniendo por ello la preferencia para que se le constituya un derecho de aprovechamiento provisional sobre las aguas subterráneas derivadas de tales obras y mientras ellas se mantengan".

Es positiva y se valora la inclusión de esta norma, pues a partir de la sobreexplotación que muchas veces se hace de los acuíferos, son los mismos usuarios a quienes se les permite recargarlos artificialmente.

Además, pese a que esta norma esta inserta dentro de lo que significa declarar una zona de restricción, compartimos el criterio de ley en el sentido de que la recarga de un acuífero pueda hacerse siempre, no importando que se haya o no declarado su restricción. Esto último debido a que como parte de la gestión de un acuífero, objetivo fundamental en caso de existir una comunidad que lo administra, debe estar siempre, no solo el preocuparse de su eficiencia y vulnerabilidad, sino también, de su viabilidad futura, siendo para ello, en caso que lo amerite, la recarga artificial un medio idóneo para su sustentabilidad. La autorización de la DGA para realizar esta gestión es conveniente, pues la recarga de no ser compatible con la calidad del agua contenida en el acuífero puede tener consecuencias futuras perjudiciales. Esto implica que los acuíferos, más allá de su conectividad al ciclo hidrológico, deben ser manejados a partir de su rendimiento indefinido en el tiempo, siendo en ese caso indispensable para su futuro la recarga artificial, lo cual será aún más necesaria cuando el acuífero sea de aquellos que no están sujetos a una recarga natural. Esta medida, en definitiva tiene por objeto entregarle a los particulares la responsabilidad de mantener los equilibrios del acuífero sin recarga natural. Sin embargo, hacemos la salvedad que deben existir incentivos correctos para que los particulares puedan realizar la recarga, ya sea por un titular de un derecho de aprovechamiento individualmente considerado, o por la comunidad en su conjunto, en caso que exista.

Por ello, un sistema de tasas por extracción como lo propone Solanes $^{19}$ o el establecer un subsidio para quien realice la recarga artificial, parecen ser incentivos adecuados, ya sea para castigar a quien más utiliza el agua del pozo a costa de otros, pues produce una externalidad negativa que los restantes usuarios no están jurídicamente obligados a soportar, o para premiar a quien hace gestiones para mantenerlo sustentable en el tiempo, subsidiándose así a quien hace intentos por mantener el óptimo del rendimiento del pozo.

19 Solanes R., Miguel (2002) "Aguas Subterráneas: necesidades regulatorias". Actas de las IV Jornadas de Derecho de Aguas. Pontificia Universidad Católica de Chile. Revista de Derecho Administrativo Económico, Vol. IV/ No 1, pp. 13-19. 
Junto a estos incentivos, nos parece que el estímulo ya definido en la ley, esto es, que mediante la realización de la recarga artificial de los acuíferos se tiene la preferencia para que se constituya un derecho de aprovechamiento provisional sobre las aguas subterráneas derivadas de tales obras mientras ellas se mantengan, es apropiado, pues se estimula a quien pese a que la zona sobre la cual se realiza la recarga es declarada zona de restricción, hace un aporte con el objeto de revitalizar el acuífero. Eso sí, la ley nada dice respecto de quien ya tiene un derecho constituido y hace una recarga con el objeto de terminar con esa situación. En ese caso, parece acertado seguir la política del subsidio, pues debe premiarse a quien, pese a ya tener un derecho definitivo, permite la entrada de nuevos solicitantes terminando con las barreras de entrada al mercado de dichas aguas ${ }^{20}$.

Por último, esta norma podría ser aplicable a la constitución de derechos de aguas sobre acuíferos que poseen volúmenes de aguas embalsamados. Si bien para la autoridad en ese caso no existiría disponibilidad del recurso (apreciación que es discutible), el hecho que a partir de ahora se permita la recarga artificial de acuíferos, hace inaplicable la postura anterior, pues pese a que su nivel de almacenamiento se encuentra estático, por medio de la descarga que significaría su utilización, y la recarga artificial posterior sujeta a control y la necesaria fiscalización de la DGA, todo hace pensar que su nivel debiera mantenerse ${ }^{21}$.

\section{RECARGA ARTIFICIAL Y CONSOLIDACIÓN DE DERECHOS DE APRO- VECHAMIENTO DE AGUAS PROVISIONALES (ARTÍCULO 67)}

Finalmente, el último artículo modificado por parte del legislador referido al capítulo de las aguas subterráneas es este, cuya oración final de su primer inciso fue reemplazada por la siguiente:

"Lo anterior no será aplicable en el caso del inciso segundo del artículo 66, situación en la cual subsistirán los derechos provisionales mientras persista la recarga artificial".

20 La Contraloría, por medio del Dictamen $N^{\circ} 19.545 / 2005$, ha señalado que "es improcedente la inscripción, en los Registros de Aguas de los Conservadores de Bienes Raices, de los derechos provisionales de aprovechamiento de aguas a que se refiere el artículo 66 del Código de Aguas". Por lo tanto, pese a los incentivos a que hacemos referencia, la precariedad de estos derechos sigue siendo patente.

21 CANUT DE BON L., Alejandro (2000) "Derechos de aprovechamiento sobre aguas subterráneas almacenadas". Revista de Derecho Administrativo Económico, Vol. II/No 1, pp. 75-83; y Housron, John y otros (2001) "Constitución de derechos de aprovechamiento sobre aguas subterráneas almacenadas". Revista de Derecho Administrativo Económico, Vol. III/ $\mathrm{N}^{\circ} 1$, pp. 117-127. 
Este artículo prescribe, en concordancia con el artículo 66, que los derechos provisionales otorgados en conformidad al inciso anterior, se podrán transformar en definitivos una vez transcurridos cinco años desde el ejercicio efectivo de estos en los términos concedidos, y siempre que los titulares de derechos ya constituidos no demuestren haber sufrido daños. Ahora, no solo se podrán transformar dichos derechos en definitivos cuando se hayan ejercido de manera interrumpida durante cinco años; y, además, no hayan sido los titulares de los derechos ya constituidos lesionados en sus derechos, sino que podrán ejercer el mismo derecho, también, cada vez que ejecuten obras de recarga. Eso sí, siempre que la recarga artificial incorpore un caudal equivalente o superior a la extracción que se efectúe.

Así, si un titular hace una recarga artificial y la quiere aprovisionar, se transformará en definitivo. Esta es la lógica que sigue la reforma. Da la impresión de que basta con que se ejecute una recarga artificial por una sola vez y el derecho se transformará en definitivo, pero aquello no es efectivo, ya que supone, y ese es el espíritu de la ley, que el derecho es a perpetuidad. En consecuencia, la recarga debe ser permanente para obtener el beneficio de la consolidación de los derechos. Esto se debe a que las recargas artificiales requieren un alto costo y nivel de manutención, y este derecho subsiste bajo la condición de que se mantenga dicha recarga. Así, lo que se pretende finalmente es que subsistan, más que fluctuaciones, determinados volúmenes de recarga en el largo plazo, los cuales mientras permanezcan estables, junto con la no lesión de los derechos de titulares de derechos ya constituidos, podrán hacerse definitivos aquellos derechos que en algún momento fueron temporales o provisionales.

No podemos más que concordar plenamente con la modificación realizada, pues va en la línea de reconocer derechos y no de limitarlos. Esto, debido a que contrariamente a lo que hemos comentado con anterioridad, en este caso, lo que se pretende, es entregar seguridad jurídica, permitiendo que lo que en un minuto era provisorio y temporal, y siempre que se cumplan ciertas condiciones razonables y prudentes, el derecho que en un momento estaba destinado a extinguirse (condición resolutoria), se consolide definitivamente, radicándose de manera coherente y estable en el patrimonio de su titular.

Tanto esta reforma, como la que comentamos con anterioridad (artículo 66) van en línea de reconocer que la demanda por recursos hídricos va en aumento, siendo indispensable otorgar a los particulares mecanismos de recarga de la fuentes (acuíferos) con el objeto de recuperar la sustentabilidad de ellos, lo que da un contenido de realismo a la reforma que analizamos.

Por último, es de esperar que la DGA especifique y distinga, de buena forma, la manera en que la recarga de los distintos acuíferos debe 
realizarse, ya sea de aquellos acuíferos fácilmente recargables o de baja profundidad, artesianos (profundos) o $\operatorname{costeros}^{22}$, pues la realidad de cada uno de ellos es distinta y debería estar sujeta a una reglamentación diferente.

\section{ASPECTOS ADMINISTRATIVOS QUE COMPLEMENTAN LA REFORMA A los artículos 65, 66 Y 67 DEL Código de Aguas. EXPlota- CIÓN DE AGUAS SUBTERRÁNEAS}

Las modificaciones hechas a los artículos 65, 66 y 67 del Código de Aguas deben también entenderse a partir de su reglamentación complementaria, esto es, la nueva Resolución No 341 de 2005 de la DGA. Esto último, debido a que buena parte de su regulación complementaria contenida en la anterior resolución fue modificada en orden a ajustarse a los cambios que la nueva modificación al Código de Aguas imponía.

\section{(9.1.) Declaración de una zona de restricción}

El nuevo artículo 31 de la Resolución que comentamos, complementando la idea del artículo 65 del Código de Aguas, en orden a declarar zonas de restricción, prescribe:

"La Dirección General de Aguas deberá declarar un determinado sector bidrogeológico de aprovechamiento común como área de restricción para nuevas explotaciones de aguas subterráneas, de oficio o a petición de cualquier usuario del respectivo sector, cuando los estudios técnicos demuestren que la explotación previsible del acuífero ocasionará alguno de los siguientes efectos...:".

Como puede apreciarse, el artículo 31 obliga, al igual que el inciso segundo del artículo 65 del Código de Aguas, a declarar una zona de restricción, pues ambas normas utilizan el verbo "deberâ", quitándole así el carácter facultativo que pudiese llegar a tener esta medida, transformándola en obligatoria en caso que concurran las circunstancias que contempla la norma administrativa. Eso sí, advertimos que la redacción de esta norma es mucho más imperativa y a la vez más precisa que la legal, ya que esta última señala que: "cuando los antecedentes sobre la explotación del acuífero demuestren la conveniencia de declarar área de restricción de conformidad con lo dispuesto en el inciso anterior, la Dirección General de Aguas deberá asi decretarlo". Es decir, esta norma da cierto margen para que la autoridad, en caso que sea "conveniente" declare una zona de restricción. de Derecho Administrativo Económico. Vol. III/No 2, pp. 539-545. 
Así, la obligación nace solamente cuando sea "oportuno" o "provechoso" declarar dicho tipo de zona, y ella no ha sido declarada, lo que da finalmente a la DGA cierto margen de elasticidad en la toma de este tipo decisiones, pues es ella la que estima la conveniencia de dicha medida. Además, esta obligación, a diferencia de la legal, nace cuando los "estudios técnicos demuestren que la explotación previsible del acuífero ocasionará alguno de los siguientes efectos...". O sea, a partir del artículo 31, ya no es la conveniencia o no de declarar dicha zona, sino que serán estudios técnicos los que deberán avalar dicha decisión, reduciendo, solo en parte, la discrecionalidad de la DGA para decretar dicha medida.

Pese a lo anterior, no hay una norma que dé una solución para el caso de que concurriendo las circunstancias descritas, esta no se dicte. En ese caso, podrían ser aplicables las normas referentes a responsabilidad del Estado (artículo 38 inciso segundo de la Constitución) si se produce un daño grave por la omisión de dicha medida, y las normas referentes a la acusación constitucional en contra de un Ministro de Estado (artículo 52 letra b) de la Constitución) en caso de que este (Ministro de Obras Públicas) infrinja las layes o las haya dejado sin ejecución.

Ahora, ¿cuáles son los efectos que deben demostrar los estudios técnicos para declarar zona de restricción?

El artículo 31 señala que deben producirse alguno de los siguientes efectos:

“a) Que los descensos generalizados provoquen el agotamiento de algunas zonas del acuífero, imposibilitando la extracción de aguas subterráneas de derechos de aprovechamiento existentes en dichas zonas. b) Que la recarga del acuífero sea superada, produciendo descensos sostenidos de sus niveles, al grado que provoque reducciones superiores al cinco por ciento del volumen almacenado en un plazo de cincuenta años. c) Que se produzca afección a las caudales de los cursos de aguas superficiales y vertientes en más de un diez por ciento del caudal medio de estiaje del año con una ochenta y cinco por ciento de probabilidad de excedencia, afectando derechos de aprovechamiento existentes. d) Que exista peligro de contaminación del acuífero por desplazamiento de aguas contaminadas o de la interfase agua dulce-salada en sectores próximos a aguas salobres, comprometiendo las captaciones existentes. e) Que exista peligro de afección al medio ambiente en los sectores protegidos indicados en el artículo 22 letra $f$ ) de la presente resolución".

Estos efectos, a diferencia de lo contemplado en la Resolución $N^{\circ} 186$ de 1996, son verdaderamente efectos (así los llama la resolución), es decir, son consecuencias y no circunstancias (palabra cuyo significado es más amplio), como utilizaba la Resolución de 1996, lo que aumentaba la elasticidad por medio de la cual se podía hacer uso de estas causales. Además, estos efectos son más precisos que los anteriores, lo que reduce, pero no elimina, la discrecionalidad por medio de la cual la DGA puede dictar esta medida. Afortunadamente, ya no se habla, como lo hacía la anterior Resolución, de estudios que demuestren que existe riesgo gene- 
ralizado (no acotado ni preciso) de los niveles estáticos en el largo plazo (ahora se fijan plazos) que afecten la capacidad productiva de los acuíferos; o de que exista peligro de contaminación de este por intrusión de aguas que perjudiquen los aprovechamientos usuales, sino que a partir de la reforma a la Resolución $\mathrm{N}^{\circ} 186$, hoy $\mathrm{N}^{\circ} 341$, se habla de los mismos descensos generalizados, pero precisando de la letra a) a la f) los efectos previos que deben producirse para declarar la restricción de un acuífero.

De esta forma, se aprecia que esta norma no solo ha aumentado en cantidad, sino también en precisión (cualidad), lo que, como dijimos en su oportunidad, no disminuye la discrecionalidad, pero si la reduce, pues no debe olvidarse que estas casuales, al menos sus enunciados generales, debieron haber estado plasmadas en la ley, dejando a la potestad reglamentaria la precisión de porcentajes u otras variables.

\section{(9.2.) Otorgamiento de derechos provisorios}

Asimismo, el inciso segundo del artículo 32 de la Resolución contempla un mecanismo adecuado. Este prescribe que los derechos de "aprovechamiento otorgados provisionalmente se anotarán en un registro especial del Registro Público de Derechos de Aprovechamiento de Aguas del Catastro Público de Aguas". Es decir, no solo los derechos definitivos se registran, sino también aquellos de carácter provisorio, lo que es adecuado, pues permite tener certeza, desde un comienzo, respecto de quienes son titulares de estos derechos. Esto, además, permite tener una mayor información (elemento clave en todo mercado) respecto de la asignación de las aguas, y saber de manera precisa quién tiene un derecho y de que naturaleza son, y así hipotéticamente fijar su precio.

Por su parte, el inciso segundo del artículo 33 del mismo cuerpo legal, contempla que el procedimiento referido a la solicitud para transformar los derechos provisionales en definitivos, "se tramitará de conformidad con el procedimiento administrativo previsto en el párrafo $1^{\circ}$ del Título I del Libro Segundo del Código de Aguas", debiendo ser dicha solicitud "notificada además, a la comunidad de aguas que se forme con motivo de la declaración de área de restricción, en la forma y términos dispuestos en el artículo 131 inciso final del Código de Aguas". Es positivo que la DGA haya remitido al procedimiento legal contemplado en el Código de Aguas la regularización de los derechos provisionales a definitivos, pues demuestra, al menos en este punto, una clara visión garantística, al entender que debe ser la ley y no una norma de rango inferior la que determine el procedimiento cuando lo que se pretende es la constitución de un derecho.

Sin embargo, los incisos finales del artículo 33 entregan los criterios mediante los cuales la DGA resolverá si los derechos provisionales se transforman en definitivos, siendo estos distintos de los que la ley contempla. El artículo 67 es claro al señalar que "La Dirección General de 
Aguas declarará la calidad de derechos definitivas a petición de los interesados y previa comprobación del cumplimiento de las condiciones establecidas en el inciso precedente".

¿Cuáles son estas condiciones?

1) Una vez que hayan transcurridos cinço años de ejercicio efectivo en los términos concedidos; y

2) Siempre que los titulares de derechos ya constituidos no demuestren haber sufrido daño.

Por su parte el artículo 33 en su inciso tercero exige, además de las condiciones establecidas en la ley, el hecho que "la explotación del respectivo acuifero sea la apropiada para su conservación y protección en el largo plazo". Además, agrega que no solo dejará sin efecto estos derechos si hay daño a los derechos ya constituidos, sino que junto a ello, cuando hayan habido perjuicios al "medio ambiente, o bien se atente contra la apropiada conservación y protección del acuífero". Es decir, no basta la seguridad que otorga la ley, requisitos extremadamente precisos para determinar si los derechos provisionales se transforman en definitivos o no, pues a ellos se agregan, por la propia Resolución, conceptos de dudosa determinación jurídica como lo son "la apropiada conservación para la protección en el largo plazo" del acuífero. Junto a lo anterior, la resolución agrega como requisito el no haber dañado el "medio ambiente" y que no se atente "contra la apropiada conservación y protección del acuífero". Se concluye así que no son tan solo dos los requisitos necesarios para que los derechos provisionales se transformen en definitivos, sino que cinco, entre los cuales está, por ejemplo, el no dañar el medio ambiente.

\section{(9.3.) Recarga artificial de acuíferos}

Finalmente, el artículo 34 en lo referido a la recarga de acuíferos, da los criterios para quienes deseen ejecutar obras de recarga artificial de acuíferos. Para ello, deberán entregar una memoria técnica que contenga a lo menos lo siguiente:

“a) Descripción del sistema de recarga artificial. b) Descripción de la naturaleza física y situación jurídica del agua a utilizar en la recarga artificial. c) Descripción del sitio de recarga. d) Características geológicas e hidrogeológicas del sector. e) Características de la zona no saturada. f) Características de acuífero. g) Velocidad y dirección de flujo. b) Comportamiento bistórico de los niveles de agua en el sector. i) Calidad del agua. j) Impactos asociados a la obra de recarga artificial. Área de influencia de la recarga artificial, impactos calculados, análisis de domos e impacto sobre la calidad del agua. k) Plan de monitoreo, que contemple al menos: 1) monitoreo del nivel de las aguas. 2) monitoreo de la calidad de las aguas. 3) control del caudal de recarga. 4) control de extracciones. l) Plan de contingencia, que contemple al menos: 1) medidas de protección del acuífero. 2) planes de alerta ante impactos no deseados". 
Por ser la recarga un asunto de suma importancia en la vida del acuífero, es que la DGA exige de manera detallada un memoria técnica, donde se contenga una declaración precisa de la forma en que la recarga se realizará. Lo que se pretende es que preventivamente, por medio de esta declaración, se eviten posibles daños al acuífero como a titulares de otros derechos ${ }^{24}$.

\section{CONCLUSIÓN}

De los antecedentes expuestos, se desprende que la regulación de la aguas subterráneas ha sido completamente modificada, tanto legal como administrativamente. Sin embargo, pese a lo trascendental de la reforma, advertimos, cuestión permanente en esta disciplina, que la actual regulación de las aguas subterráneas sigue sustentándose mayormente en una norma de rango administrativo (Resolución $\mathrm{N}^{\circ} 341$ ), lo que atenta contra estándares de seguridad jurídica que una actividad como esta debe poseer, pues la exploración y la explotación de aguas subterráneas queda, desde el punto vista fáctico, en manos de la DGA, desnaturalizando y afectando, al menos en estos casos, la esencia de derechos de rango constitucional, como lo son, el de propiedad (19 $\mathrm{N}^{\circ}$ 24) y el desarrollo de actividades económicas ( $19 \mathrm{~N}^{\circ} 21$ ), especialmente, por ejemplo, cuando la DGA de oficio puede declarar una zona de restricción de un acuífero (art. 65). No es posible, y ahí radica el problema y la insuficiencia de la actual reforma, sin perjuicio de los positivos alcances que ella tiene en otros aspectos, que una norma administrativa, ya modificada dos veces (años 1996 y 2005) regule aspectos tan trascendentes para el futuro hídrico del país. El legislador debió haber profundizado, mediante su instrumento (la ley), los cambios realizados en este tipo de aguas, pues la remisión amplia y poco delimitada que hace la ley a la DGA, priva de manera importante de la seguridad y estabilidad necesaria para el desarrollo de este tipo de actividades económicas y proyectos de inversión. Es de esperar que a futuro esta situación sea superada y corregida legalmente.

23 MuÑoz Rodríguez, Jaime (2001) "Gestión de aguas subterráneas, derechos provisionales y recarga artificial de acuíferos". Actas III Jornadas de Derecho de Aguas. Pontificia Universidad Católica de Chile. Revista de Derechos Administrativo Económico. Vol. VIII/N ${ }^{\circ}$, pp. 519-526. 


\section{BIBLIOGRAFÍA CITADA}

- Alarcón Jaña, Pablo (2000) "Discrecionalidad administrativa. Un estudio de la jurisprudencia chilena". Santiago: LexisNexis.

- Bulnes Aldunate, Luz (1985) "El derecho a desarrollar cualquier actividad económica". Revista de Derecho Público, No 37-38.

- CANUt De BON L., Alejandro (2000) "Derechos de aprovechamiento de sobre aguas subterráneas almacenadas". Revista de Derecho Administrativo Económico. Vol. II/ N ${ }^{\circ} 1$.

- Cea Egaña, José Luis (2004) Derecho Constitucional Chileno. Derechos, Deberes y Garantías. Tomo II. Santiago. Ediciones Universidad Católica de Chile.

- Custodio, Emilio (1976) Hidrología Subterránea. Barcelona: Editorial Omega.

- Fermandois Vöhringer, Arturo (2006) Derecho Constitucional Económico. Garantías Económicas, Doctrina y Jurisprudencia. Tomo I. Santiago: Ediciones Universidad Católica de Chile.

- Houston, John y otros (2001) "Constitución de derechos de aprovechamiento sobre aguas subterráneas almacenadas". Revista de Derecho Administrativo Económico. Vol. III/N $\mathrm{N}^{\circ} 1$.

- MUÑOz Rodríguez, Jaime (2001) "Gestión de aguas subterráneas, derechos provisionales y recarga artificial de acuíferos". Actas III Jornadas de Derecho de Aguas. Pontificia Universidad Católica de Chile. Revista de Derecho Administrativo Económico. Vol. VIII/N $\mathrm{N}^{\circ} 2$.

- PALACIOS GONZÁlEZ, Galvarino (1987) "La garantía constitucional del racional y justo proceso", Gaceta Jurídica $\mathrm{N}^{\circ} 84$.

- Solanes R., Miguel (2002) "Aguas Subterráneas: necesidades regulatorias". Actas IV Jornadas de Derecho de Aguas. Pontificia Universidad Católica de Chile. Revista de Derecho Administrativo Económico. Vol. IV $/ \mathrm{N}^{\circ} 1$.

- Soto Kloss, Eduardo (1982) El Recurso de Protección. Orígenes, doctrina y jurisprudencia. Santiago: Editorial Jurídica de Chile.

- Verdugo Marinkovic, Mario y otros (1994) Derecho Constitucional. Tomo I. Santiago: Editorial Jurídica de Chile.

- Vial del Río, Víctor (2000) Acto Jurídico y Personas. Teoría General del Acto Jurídico. Santiago: Ediciones Universidad Católica de Chile.

- Vergara Blanco, Alejandro (2004) "Discrecionalidad Administrativa y nuevas limitaciones a los derechos de agua". Puntos de Referencia. CEP No 276.

Jurídica de Chile.

(1998) Derecho de Aguas. Tomo I. Santiago: Editorial

- WhitTow, John (1988) Diccionario de Geografía Física. Madrid: Alianza Editorial. 
- Zañartu Rosselot, Hipólito (2001) "Aguas Subterráneas: ¿Necesidad de un nuevo enfoque?" Actas III Jornadas de Derecho de Aguas 2000. Revista de Derecho Administrativo Económico. Vol. VIII/No 2.

- Zapata larraín, Patricio (1994). La jurisprudencia del Tribunal Constitucional. Santiago: Corporación Tiempo 2000.

\section{JURISPRUDENCIA CITADA}

- Contraloría General de la República: Dictamen No $19.545 /$ 2005.

- Revista de Derecho y Jurisprudencia: Tomo 98, sec. 7. p. 45.

- Tribunal Constitucional: Roles número 124, 146-167, 184, $185,245-246,247,253,254,282,325$ y 370. 